\title{
Apuntes históricos sobre la tarea de una metafísica de las costumbres.
}

\author{
Luciana M. Martínez, UBA, CONICET. \\ luciana.mtnz@gmail.com \\ Recibido 1/07/2016 \\ Aprobado 29/08/2016
}

Kurz, ohne Metaphysic kann kein Mensch seyn. (V-Met/K3, AA 29:948) ${ }^{1}$.

Resumen. El objetivo de este artículo consiste en especificar el significado que tiene el concepto "metafísica" para la comprensión de la tarea de la Metafísica de las costumbres. Para estudiar ese significado recurrimos a dos clases de fuentes: los elementos paratextuales de ese libro y los apuntes de clase de la época. En primer lugar, revisamos la literatura sobre el tema para determinar el período relevante de la obra kantiana. Luego, estudiamos las definiciones de "metafísica" proporcionadas en las fuentes. En tercer término, distinguimos la metafísica de otras ciencias. Finalmente, nos ocupamos de la materia propia de la metafísica de las costumbres.

Palabras clave: Kant, Metafísica, Filosofía práctica, Lecciones, Materia.

Abstract. The main purpose of this paper is to specify the meaning of the concept of "metaphysics", in order to explain the own task of the Metaphysics of Manners. With the purpose of analyzing this meaning we turn to two kinds of sources: paratextual elements in this book and the student notes in Kant's lectures. To this end, first, we study some literature about our topic, in order to specify the period. Then we analyze the definitions of "metaphysics" which are to find in the sources. Thirdly, we distinguish the metaphysics from other sciences. Finally, we study the very matter of a metaphysics of manners.

Keywords: Kant, Methaphysics, Practic philosophy, Lectures, Matter.

Se citarán las obras de Kant según el formato usado por la Kant-Gesellschaft (KANT, Immanuel. Kant's gesammelte Schriften. Ed. de la Königlich Preußischen Akademie der Wissenschaften und ihren Nachfolgern. Berlin y Leipzig, 1900ss.), indicando el volumen y el número de página de las referencias en esta edición. 


\section{Introducción}

Cuando comenzamos a leer la Metafísica de las costumbres (MS), publicada en 1797, lo primero que encontramos en ella, en su prólogo, es una indicación acerca del lugar que ella ocupa en el marco de la filosofía kantiana. La metafísica de las costumbres (i) sigue a la crítica de la razón práctica y (ii) es la parte sistemática de la investigación filosófica en el ámbito del uso práctico de la razón. Con respecto a lo primero, desde la emergencia del sistema crítico $^{2}$, Kant es enfático acerca de este punto: antes de la metafísica es necesario llevar a cabo una tarea preliminar, una propedéutica. La filosofía crítica tiene dos momentos: un momento preliminar, el de la crítica de la razón, y el momento sistemático, que es el de la metafísica.

Además, la metafísica admite una partición en dos ciencias, fundamentada en la naturaleza de su objeto: una metafísica de la naturaleza y una metafísica de la libertad (o de las costumbres). Así, la filosofía kantiana debe contener, por lo menos ${ }^{3}$, una crítica de la razón en su uso teórico, una metafísica de la naturaleza, una crítica de la razón práctica y una metafísica de las costumbres. Hasta la emergencia de la MS, Kant sólo había completado el proyecto crítico y la metafísica de la naturaleza. La Metafísica de las costumbres completa el sistema de la filosofía ${ }^{4}$.

La pregunta que sirve de hilo conductor para este trabajo es la siguiente: ¿qué características tiene una metafísica de las costumbres? ¿Qué tipo de ciencia es? ¿Cómo debe proceder? ¿De qué se ocupa? Para responder a esta pregunta recurrimos a dos tipos de texto. En primer lugar, estudiamos apuntes de clase de los alumnos de Kant, en los cuales se encuentra una explicación de la naturaleza, el tema y los límites de esa ciencia. El beneficio que proporciona el estudio de estos textos está dado por su naturaleza didáctica, que favorece el desarrollo expositivo y facilita la claridad de las explicaciones. En estos textos se desarrollan, como veremos, numerosos aspectos de la metafísica de las

\section{Cf. Diss, AA 2: 411.}

3 En la segunda mitad de la década de 1780, además, Kant descubrió que la tarea crítica requería también una investigación del Juicio.

4 Hasta aquí, seguimos las tesis de CORTINA ORTS, Adela (1989). "Estudio preliminar". En: KANT, Immanuel, La metafísica de las costumbres. Madrid, Tecnos, 1989. 
costumbres como ciencia que el libro de Kant apenas bosqueja.

En segundo lugar, estudiaremos el texto de la Metafísica de las costumbres. Este texto se publicó en 1797 y se divide en dos partes, que antes habían circulado por separado. En la primera de ellas, Kant proporciona una metafísica del derecho. En la segunda, encontramos su doctrina de la virtud. Además, el texto contiene un prólogo y una introducción. En estos elementos paratextuales, Kant se ocupa de manera explícita de dar una respuesta para nuestros interrogantes, si bien esa respuesta en algunos puntos parece oscura y demanda cierto esfuerzo para su comprensión. Nuestro estudio se centrará en esta parte del libro, y no en las secciones del derecho y la virtud.

\section{Acerca de la evolución del concepto de metafísica en el pensamiento de Kant.}

La definición del concepto de "metafísica" es un tema que Kant abordó constantemente a lo largo de su obra. Pero si bien ese tema se repite, no es el caso que la caracterización de ese concepto tan importante sea exactamente la misma en los diferentes textos del filósofo. El desarrollo de este tema no es asunto de esta monografía. Sin embargo, conviene que nos demoremos en las discusiones que ha generado. Aquí intentaremos revisar algunos aspectos del concepto de metafísica que se presenta en la Metafísica de las costumbres. Con ese fin, veamos algunas consideraciones acerca de la evolución de ese concepto en el pensamiento de Kant, para decidir qué textos es prudente utilizar como fuentes.

María Jesús Vázquez Lobeiras ${ }^{5}$ considera que podemos encontrar una noción crítica de la metafísica y que esa noción se presenta por primera vez en la disertación de 1770. Para esta comentadora, además, desde su emergencia, el concepto crítico de metafísica alberga en su seno el proyecto ético de Kant ${ }^{6}$. Según esto, en el marco del pensamiento de

5 VÁZQUEZ LOBEIRAS, M. J. "La ética kantiana como una parte de la metafísica. Reflexiones en torno a la evolución del pensamiento ético de Kant en el bicentenario de la Metafísica de las costumbres (17971997)". En CARVAJAL CORDÓN, J. (Ed.), Moral, derecho y política en Immanuel Kant. La Mancha, Cuenca, 1999, pp. 321-332.

6 En este artículo, además, Vázquez Lobeiras suscribe la tesis de que en la disertación de 1770 tiene lugar un giro metodológico en el pensamiento de Kant. La comentadora entiende esta variación como un cambio en la consideración del punto de partida de la metafísica. Desde la disertación, señala Vázquez Lobeiras, la metafísica no puede tomar como punto de partida representaciones empíricas, algo que en 
Kant acerca de la metafísica encontramos una primera intervención crítica respecto de la tradición por lo menos en la Disertación de $1770^{7}$.

Gabriel Rivero, por su parte, sostiene que hay otra modificación relevante en la concepción kantiana de la metafísica que debe datarse en 1787. Este comentador concuerda con la tesis de Vázquez Lobeiras. Para él, hasta 1781, año de la publicación de la Crítica de la razón pura, deben reconocerse tres momentos. En el primero de ellos, previo a la Disertación, Kant habría tenido una concepción de la metafísica idéntica, en lo esencial, a la de Baumgarten. En las reflexiones de 1769, Kant habría comenzado a distanciarse, en cambio, de él. Para Rivero, los aspectos esenciales de ese distanciamiento se vinculan con la combinación de la investigación de los límites, la razón humana y lo subjetivo. Finalmente, en la primera edición de la Primera Crítica, Rivero encuentra una concepción de la metafísica que tiene dos aspectos. Por una parte, en el Prólogo se presenta una visión negativa de esa ciencia en la que todo es confusión. Por la otra, en la "Arquitectónica de la razón pura", que es un capítulo de la "Doctrina transcendental del método", la metafísica se presenta como una ciencia racional por meros conceptos, cuyos objetos son la naturaleza y la libertad.

Ahora bien, prosigue Rivero, la definición de metafísica que encontramos en la primera edición de la Primera Crítica no es la definitiva. El texto Los progresos de la metafísica contiene una definición diferente y el objetivo del artículo de Rivero consiste en especificar esa diferencia y situar su origen. La especificidad del concepto de metafísica que encontramos en este texto consiste en la inclusión de lo suprasensible. El origen de

los textos previos de Kant, según la comentadora, sí era posible. Esta tesis histórica reviste especial interés, incluso en estrecha relación con el tema de este trabajo. Pero su discusión excede los límites de esta investigación. Señalemos que si bien seguimos a Vázquez Lobeiras con respecto a la emergencia de un nuevo concepto de metafísica en la Disertación, suspendemos el juicio en lo que a la cuestión metodológica se refiere.

7 Sobre el concepto de Metafísica que se desarrolla en la Disertación de 1770 y las novedades de este concepto con respecto a la tradición racionalista, puede hallarse una presentación detallada en: MOLEDO, F. "Die neue Auffassung der Metaphysik als reine Philosophie in der Inauguraldissertation und ihre propädeutische Bedeutung m Rahmen der Entwiklungsgeschichte der KrV". En: Kant-Studien, 2015. Acerca de las innovaciones que se presentan en la Disertación, no en cuanto al concepto de Metafísica, sino en cuando a sus contenidos, puede hallarse un desarrollo detallado en SÁNCHEZ RODRÍGUEZ, Manuel. "La teoría de los tipos de representación en Leibniz y sus principales influencias en la estética y la lógica de la Ilustración alemana". En: Cultura. Revista de História E Teoria Das Ideias (Universidade Nova de Lisboa, 2014. 
ese cambio se encuentra, según la argumentación de Rivero, en dos series de textos de $1786^{8}$ y $1787^{9}$. Es decir, el surgimiento del nuevo concepto de metafísica es contemporáneo con la emergencia de la Crítica de la razón práctica y de la segunda edición de la Crítica de la razón pura. Si queremos estudiar el significado de metafísica en el período de la Metafísica de las costumbres, entonces conviene que nos ocupemos de especificar cuáles son los rasgos de ese concepto en este momento del pensamiento kantiano.

Ese concepto, prosigue Rivero, se encuentra definido con claridad en el texto de los Progresos. Allí, se lee que la metafísica es "la ciencia de progresar del conocimiento de lo sensible a lo suprasensible a través de la razón" ${ }^{10}$. En él destacan algunos aspectos. En primer lugar, la metafísica es una ciencia. Esto significa para Kant que constituye un sistema de conocimientos, y no un mero agregado. El carácter sistemático de la ciencia está dado por el hecho de que la totalidad de los conocimientos se ordenan en conformidad con una idea de la razón que los ordena. En segundo lugar, esta ciencia involucra un progreso. Finalmente, ese progreso avanza desde lo sensible hacia lo suprasensible. ${ }^{11}$

Cada vez que Kant necesita especificar el ámbito, el objeto o el método de la metafísica, retoma la tripartición de las ciencias propuesta antes por Wolff. En el extenso discurso preliminar de su Lógica latina, Wolff exhibe una clasificación de las ciencias en tres grupos, motivada en la naturaleza del objeto que investiga cada una ${ }^{12}$. Esos grupos son: el de las ciencias históricas, el de la matemática y el de la filosofía. Una y otra vez, cuando Kant desarrolla la especificidad de la filosofía, las ciencias con las que la establece un contraste son las ciencias empíricas (en los términos de Wolff, las históricas) y la matemática. A diferencia de Wolff, que encuentra una continuidad metodológica entre la

8 La reseña del libro de Jakob y el texto “¿Qué significa orientarse en el pensamiento?”.

9 La segunda edición de la Crítica de la razón pura y la Crítica de la razón práctica.

10 FM, AA 20:260.

11 RIVERO, Gabriel. "La influencia de Pistorius en la definición kantiana de la metafísica a partir de 1787". En: Cadernos de Filosofia Alemã, 19(2), 2014, pp. 111-130.

12 WOLFF, Christian. Discursus praeliminaris de philosophia in genere. Einleitende Abhandlung über Philosophie im allgemeinen. Edición histórico crítica bilingüe de Günter Gawlick y Lothar Kreimenthal. Stuttgart-Bad Cannstatt, 1991, esp. Capítulo 1. 
filosofía y la matemática, Kant es insistente con respecto a la diferencia entre ambas ciencias en todos sus aspectos. La presentación de la metafísica de las costumbres como una metafísica en la introducción de la MS también contiene ese tipo de argumentación. La metafísica de las costumbres se diferencia con nitidez tanto con respecto a la matemática como respecto de las ciencias empíricas (en particular, la antropología), como veremos.

Analizaremos cómo caracteriza Kant la metafísica en los paratextos de la MS. Ella se presenta como un sistema de conocimientos a priori a partir de meros conceptos. Es decir, como una ciencia racional discursiva. En esta elucidación del concepto de metafísica encontramos una definición propia del período crítico del pensamiento kantiano, pero no hallamos la referencia a lo suprasensible que según Rivero, como hemos visto, es característica del concepto de metafísica que se introduce desde $1786 / 87$ y se plasma con mayor precisión en el texto póstumo Los progresos de la metafísica. Esto no significa, no obstante, que en la MS la metafísica no se encuentre referida a lo suprasensible. Por el contrario, la metafísica de las costumbres tiene por objeto las leyes de la libertad. Pero el concepto de la libertad es un concepto de la razón. Es decir, es un concepto que no tiene instancias empíricas. Desde el punto de vista teórico, es un concepto trascendente. ${ }^{13}$

La investigación de Gabriel Rivero se concentra en los textos publicados por Kant. Contamos con otro tipo de fuentes que también arroja luz al concepto de la metafísica introducido a mediados de la década de 1780. Se trata, a saber, de los apuntes de clase tomados por sus alumnos ${ }^{14}$. En esos apuntes encontramos un desarrollo en ocasiones más detallado del concepto de metafísica $y$, en relación específica con el tema que investigamos, de la situación de la filosofía práctica en el marco de ella. Los apuntes de Metafísica correspondientes al período entre 1786 y la MS, de 1797/98 disponibles en la

13 MS, AA 6:221

14 El estudio de este tipo de fuentes reclama ciertos reparos metodológicos. Si bien las anotaciones eran generalmente literales, es necesario tener siempre presente, en primer lugar, la medación del copista. En algunos casos, además, no se encuentra suficientemente determinada la datación y la autoría de los ejemplares. Finalmente, los cursos de Kant seguían, según la usanza de la época, manuales. En algunos puntos no es una tarea simple deslindar las tesis de Kant de las de los textos comentados. Las dificultades propias del estudio de los apuntes han sido señaladas por María Jesús Vázquez Lobeiras en su edición española de la Jäsche Logik (Madrid, Akal, 2000). También se detallan en el estudio introductorio de Reinhard Brandt y Werner Stark para la edición académica de las lecciones de Antropología (AA 25). 
edición académica de las obras de Kant son los siguientes: i) Metaphysik von Schön (178590), ii) Metaphysik K2 y Metaphysik Pölitz L2 (1790/91), iii) Metaphyisik Dohna (1792/93), iv) Metaphysik K3 (1794/95). En estos apuntes, la mayoría de ellos fragmentarios, la explicación del concepto de metafísica se encuentra en las primeras páginas, que constituyen una introducción general a la materia del curso. A continuación, a la luz de esos apuntes y de los elementos paratextuales de la Metafísica de las costumbres procuraremos hacer un comentario detallado de los rasgos que tiene esa ciencia para Kant en el período en el que publicó este libro.

\section{La metafísica es un sistema de conocimientos.}

En los primeros de esos apuntes, la Metafísica von Schön, que según la edición académica correspondería a las clases impartidas por Kant entre 1785 y 1790, la metafísica se caracteriza como un todo ${ }^{15}$, es decir, el todo de nuestro conocimiento a priori. Más específicamente, la metafísica se caracteriza como un todo sistemático: el sistema del conocimiento racional puro por meros conceptos. Que sea un sistema significa que los conocimientos se agregan metódicamente. La metafísica es un todo de conocimientos. Pero no es un mero agregado, sino un sistema. Un sistema de conocimientos es una ciencia. La metafísica es una ciencia.

Más aún, un rasgo al que es necesario atender es el siguiente: el objeto de la metafísica es tal, que podemos circunscribirlo. Esto se debe a que la metafísica es un sistema de conocimientos a priori. Es una ciencia que conoce por mera razón. El texto expresa lo siguiente:

El todo de nuestros conocimientos puros a priori o de nuestros conocimientos racionales es la metafísica, o es un sistema de conocimiento racional puro por meros conceptos. Tal ciencia está separada [abgesondert] por sí misma, totalmente aislada; la razón pura se pone [sich setzen] completamente sola. La razón es pura si no contiene nada empírico en su uso. ${ }^{16}$

Ahora bien, la metafísica es una ciencia racional que no involucra ninguna

15 Para una caracterización exhaustiva del concepto de todo (das Ganze) en la filosofía crítica de Kant, cf. DRIESCH, Hans, "Kant und das Ganze". En: Kant Studien, 29, 1924.

16 V.-Met/von Schön, AA 28: 464. 
referencia a la intuición. Ella conoce racionalmente a priori por meros conceptos, sin asegurar los conocimientos por la experiencia. Esto incrementa las posibilidades del error. $\mathrm{Ni}$ la experiencia ni la intuición pura proporcionan una piedra de toque para evaluar sus conocimientos. No hay un modo de someter a contraste sus juicios. Dada esta amenaza, la metafísica demanda una tarea previa ${ }^{17}$, que consiste en la crítica de la razón. Ésta debe indagar "1) si hay realmente una facultad de la razón pura tal, 2) si nos proporciona algo efectivo [wirklich] para conocer, y 3) si podemos determinar la extensión y los límites de la razón pura". Sólo si se elucidan esas cuestiones es posible una metafísica. Esa investigación es necesaria para que la pretendida ciencia no sea un mero conglomerado de puras quimeras, un conjunto de doctrinas vacías. ${ }^{18}$

En el segundo grupo de los apuntes mencionados, la Metafísica K2, del semestre de invierno de 1790/91, el carácter fragmentario de la sección introductoria no permite que investiguemos la noción de metafísica. En cambio, conviene estudiar la Metafísica Pölitz L2, aparentemente correspondiente, también, al semestre de invierno de 1790/91. Allí, la Metafísica se presenta como "el sistema de la filosofía pura". Y añade Kant que "[l]a palabra Metafísica significa una ciencia que sobrepasa las leyes de la naturaleza. (Naturaleza es el concepto de todos los objetos de la experiencia)" ${ }^{19}$ Si en los apuntes de la Metafísica von Schön encontramos una caracterización del concepto que se corresponde con los rasgos que según Rivero caracterizan el período previo a 1786/7, en los apuntes Pölitz L2, en cambio, la caracterización de la metafísica ya exhibe los rasgos del período posterior. Todavía se señalan el carácter sistemático y puro de esta ciencia- algo que por lo demás Kant sostendrá hasta en sus últimos textos, pero ya se indica, atendiendo a una interpretación de la etimología de la palabra, una referencia a algo que trasciende el ámbito de la experiencia.

El conocimiento filosófico y, con él, el conocimiento metafísico, es un conocimiento científico, en el que todos los conceptos son puros. Más aún, el conocimiento filosófico (y,

17 Esta "tarea previa", esta propedéutica, es la empresa crítica. Kant, como hemos señalado antes en este trabajo, era consciente de la necesidad de esta tarea por lo menos desde su Disertación, en 1770.

18 V.-Met/ von Schön, AA 28: 465.

19 V.-Meth/Pöl K2, PM 17. 
en particular, el conocimiento metafísico) es un conocimiento por meros conceptos $a$ priori. En las primeras líneas de estos apuntes encontramos una clasificación de tres tipos de filosofías. En primer lugar, la Física es la filosofía de la naturaleza en la medida en que depende de los principios de la experiencia. En segundo término, la Metafísica es la filosofía de la naturaleza, en la medida en que depende de los principios a priori. Finalmente, la moral enseña los principios prácticos de la razón. ${ }^{20}$

Encontramos algunas indicaciones acerca de lo que significa llevar a cabo una metafísica de las costumbres en el prólogo del libro que tiene ese título. En las primeras líneas de ese prólogo Kant proporciona, ciertamente, explicaciones centrales sobre las cuestiones que nos ocupan. La metafísica de las costumbres, leemos allí, constituye un sistema. Se trata del sistema del uso práctico de la razón. Este sistema va después de otro trabajo: la crítica de la razón práctica. Ésta se presenta como una propedéutica luego de la cual se espera el sistema, que es una metafísica.

El sistema de la metafísica de las costumbres tiene dos partes. Una metafísica del derecho y una metafísica de la virtud. Con respecto a la primera parte, Kant desarrolla un comentario que está estrechamente relacionado con las indicaciones acerca de la metafísica que hemos encontrado en las lecciones. La primera parte es una metafísica del derecho. Ahora bien, el concepto de derecho contiene en sí mismo una referencia a la experiencia: es un concepto dirigido a la praxis. La investigación que se presenta, sin embargo, no incluirá los elementos empíricos del concepto de derecho, es decir: los elementos empíricos a los que él está referido, sino de manera marginal.

Es interesante que el argumento kantiano para justificar esa decisión se refiera al aspecto sistemático de la metafísica y no al carácter puro de sus conocimientos. El múltiple de la experiencia al que el concepto de derecho se refiere no permite la disposición plena de los elementos de ese concepto. Por este motivo, la primera parte de la metafísica de las costumbres de Kant no será exhaustiva: sólo contendrá la parte del concepto de derecho que sí puede desarrollarse completamente. Es decir, la metafísica del derecho será, más bien, el sistema de los "principios metafísicos de la doctrina del derecho" y se ocupará de

20 V.-Meth/Pöl K2, PM 17s. 
los aspectos a priori del concepto de derecho. El argumento de Kant en el prólogo de la MS, pues, remite a un aspecto del concepto de metafísica que pertenece al período crítico del pensamiento kantiano. Se trata, a saber, del carácter sistemático de esta ciencia. Ese aspecto supone la posibilidad de delimitarla y de especificar el alcance que tienen sus conocimientos. Esto no sería posible si investigáramos los elementos empíricos que pueden estar implicados por el concepto de derecho.

Kant vuelve a referirse a la tarea propia de una metafísica de las costumbres en la segunda sección de la introducción de su libro. Esa sección se titula, precisamente: "Acerca de la idea y la necesidad de una metafísica de las costumbres". En ella, Kant afirma que la legalidad de las leyes morales supone un fundamento a priori. Sólo si tienen un fundamento de esta naturaleza esas leyes se legitiman como tales. Ahora bien, la investigación sistemática de conceptos a priori es una metafísica. Por eso, la filosofía práctica requiere una metafísica. Es decir, junto a la metafísica de la naturaleza es necesaria una metafísica de las costumbres.

En este argumento advertimos que Kant proporciona una justificación de la necesidad de una metafísica de las costumbres y, para ello, define el concepto de metafísica. Esta ciencia se presenta como un "sistema de conocimientos a priori por meros conceptos". ${ }^{21}$ En la definición se encuentran notas del concepto de metafísica que ya hemos indicado. La metafísica es, en primer lugar, un sistema de conocimientos. Es decir, un conjunto ordenado de conocimientos. El orden supone una idea rectora que indica la función de cada elemento en el todo de la ciencia. En segundo lugar, sus conocimientos son conocimientos a priori, y no son tomados de la experiencia.

Ya hemos visto que en el prólogo Kant señala que el concepto de derecho, un concepto crucial de la metafísica de las costumbres, se encuentra referido a la experiencia. Sin embargo, el texto kantiano no se ocupará de esa referencia porque ella no es susceptible de una exhibición sistemática. La Metafísica de las costumbres sólo se ocupa, por consiguiente, de elementos a priori. Finalmente, la metafísica es una ciencia discursiva. En esto, como veremos en el siguiente apartado, la metafísica se diferencia de

21 MS, AA 6:216 
otra ciencia racional, que es la matemática.

Antes de ocuparnos de ello, sin embargo, conviene que detengamos la mirada en una definición de la metafísica que se encuentra en el prólogo de la segunda parte de la MS, titulada "Principios metafísicos de la doctrina de la virtud". En este prólogo, Kant define la filosofía en general y la metafísica en particular. La filosofía se caracteriza allí como un "sistema de conocimientos racionales por conceptos". Esta definición, veremos, es característica del período crítico y se encuentra literalmente en la primera de las Críticas. La filosofía es un sistema, y no un agregado. Sus conocimientos son racionales. Y es una ciencia discursiva. La metafísica, por su parte, se caracteriza como un "sistema de conceptos racionales puros". La pureza está dada por su total independencia con respecto a la intuición. Los conceptos de la metafísica son conceptos de la razón y son puros. ${ }^{22}$

\section{La metafísica de las costumbres no es una matemática.}

En segundo lugar, por medio de esta elucidación de la noción de metafísica, Kant reitera un tópico usual en su discusión sobre las ciencias, cual es el de la diferencia metodológica de la metafísica y la matemática. Pues pueden pensarse dos formas de obtener conocimientos por razón. Es posible conocer racionalmente por conceptos, es decir: discursivamente, o bien por construcción de conceptos, en la intuición. En el apunte de Metafísica von Schön, en particular, el concepto de construcción, por medio del que nuestro filósofo especifica el procedimiento propio de la matemática, recibe un tratamiento detallado. Si la metafísica es una ciencia del conocimiento racional puro por conceptos, la matemática en una ciencia racional pura por construcción de conceptos. La construcción de conceptos sólo puede darse en la intuición. Como la matemática es una ciencia pura, la construcción de conceptos tiene lugar en la intuición pura, es decir, de acuerdo con los argumentos de la "Estética transcendental" de la primera crítica, en el espacio y el tiempo, que son las formas pura de nuestra intuición.

La metafísica, en cambio, es una ciencia discursiva. En ella no interviene la intuición, ni en su forma pura ni en su forma empírica. La metafísica es una ciencia que

22 MS, AA 6:375. 
conoce por conceptos. Esa diferencia tiene como consecuencia un rasgo distintivo de la metafísica, al que nos referíamos antes: como la metafísica es una ciencia pura por meros conceptos, sus límites pueden ser determinados con exactitud por el intelecto. No es ése el caso de la matemática, en cambio. Esta ciencia procede, como ya ha sido indicado aquí, por medio de la construcción de conceptos. Esta construcción se despliega, explica Kant, en la intuición y resulta indeterminada para el entendimiento. ${ }^{23}$

La diferenciación entre la metafísica y la matemática es un tema recurrente a lo largo de la obra de Kant. Para este filósofo la cuestión no se dirime en los términos de la materia o el objeto que tiene cada ciencia. Al igual que para numerosos filósofos de la época, el problema de la separación de ambas ciencias tiene que ver con los procedimientos para conocer en cada caso. Esto se hace patente en un artículo que Kant redactó en 1762 para participar en el concurso de la Academia de ciencias de Berlín en $1763^{24}$. En ese texto, Kant proporciona argumentos para mostrar que el método de conocimiento útil en matemáticas resulta inadecuado para obtener conocimientos metafísicos.

Ahora bien, la argumentación de nuestro filósofo se radicaliza en el período crítico de su pensamiento. En la "Doctrina transcendental del método" de la Crítica de la razón pura, en efecto, su exposición apunta a demostrar que esa diferencia metodológica se asienta en dos usos diferentes de la razón. En la matemática, la razón procede recurriendo a la intuición. Es decir, que ella construye conceptos en la intuición y es por medio de esa construcción que conocemos. En el conocimiento metafísico, en cambio, la razón procede discursivamente. Esto significa que la razón procede por medio de meros conceptos, sin recurrir a la intuición- ni a la intuición pura, ni a la intuición empírica. ${ }^{25}$

Hemos visto ya que este tema es tratado en los sucesivos cursos de Kant, de acuerdo con las anotaciones disponibles. En la MS Kant no repite esta argumentación,

23 V.-Met/von Schön AA 28: 464. En relación con la Metafísica, es interesante señalar que en este texto se encuentra la referencia a una constante amenaza para esa ciencia, que consiste en el hecho de no tener la experiencia como piedra de toque. En esta amenaza se funda la necesidad de llevar a cabo la empresa crítica. Cf. AA 28: 465.

24 Cf. Untersuchung über die Deutlichkeit der Grundsätze der natürlichen Theologie und der Moral, AA 2: 273ss.

25 Cf. "Die Disciplin der reinen Vernunft im dogmatischen Gebrauche", en Kritik der reinen Vernunft, B740ss. 
pero sí la retoma. En particular, encontramos una referencia a este tema en el prólogo del texto. La referencia es indirecta. Se inscribe en una posible objeción, de la que Kant se defiende. En el marco de una concepción de la historia de la filosofía en la que el criticismo se pretende una concepción radicalmente novedosa de la filosofía, se le podría objetar, leemos, el haber tomado su definición de la filosofía de otro sitio. En particular, se le podría haber objetado a Kant haber plagiado su concepto de la filosofía de un libro de matemática.

En la letra, el libro de Christian August Hausen intitulado Elementa Matheosos parece presentar la concepción de la matemática que Kant emplea para distinguirla de la filosofía. Sin embargo, prosigue Kant, el pensamiento de Hausen no contiene los conceptos en los que se funda la distinción kantiana. En particular, Hausen carece de la tesis de la realidad empírica y la idealidad transcendental del espacio y el tiempo, que Kant ha forjado desde 1770 y ha plasmado con claridad en la "Estética transcendental" de la Crítica de la razón pura. Sólo sobre la base de la concepción del espacio y el tiempo como las formas puras de la intuición y como intuiciones puras puede comprenderse que la matemática construya sus conceptos en la intuición (pura), en tanto que la filosofía (la metafísica) sea una ciencia racional discursiva. ${ }^{26}$

En la segunda parte de la Primera crítica, es decir: la "Doctrina transcendental del método", Kant infiere de los dos usos de la razón, i.e. el uso matemático y el uso filosófico, que el método matemático no puede ser empleado para obtener conocimiento en metafísica. El método matemático es axiomático: comienza con definiciones y procede deductivamente a partir de éstas. La argumentación de Kant en la "Disciplina de la razón pura en su uso dogmático", que es un capítulo de la "Doctrina transcendental del método", intenta demostrar que en metafísica no es posible proceder a partir de definiciones. Los objetos de la metafísica no pueden ser definidos. Esta ciencia debe comenzar su investigación con conceptos dados a priori. La representación de estos conceptos es confusa y la primera tarea de la filosofía consiste en elucidarla. La definición, que es un concepto pefecto, claro, distinto y detallado, se presenta para la metafísica como una

26 MS, AA 6:207s. 
tarea. No obstante, Kant advierte que nada garantiza que esta tarea resulte realizable. La definición de sus conceptos es para la metafísica una meta, y de ningún modo un punto de partida posible.

Conviene que advirtamos que allí Kant se refiere a un peculiar tipo de definición. El término es técnico, y Kant lo nombra con un latinismo: Definition. Para el concepto general, vago, de la definición, que incluye diversos tipos de abordaje de conceptos, Kant reserva el término germano Erklärung. Las Definitionen son exhibiciones claras, distintas y detalladas de los conceptos, es decir: son conceptos lógicamente perfectos. Ellas permiten tener una representación suficiente del objeto que se investiga. Esa representación permite que obtengamos conocimientos seguros por medio de la deducción. Como la metafísica no es capaz, en virtud de la naturaleza de su objeto y del uso de la razón que ella involucra, de proporcionar definiciones en sentido estricto, no es de esperar que ella comience con este tipo de conceptos.

De acuerdo con nuestros argumentos en este apartado, pues, la metafísica de las costumbres se presenta como una ciencia racional diferente de la matemática. En la ciencia que nos ocupa, la razón procede discursivamente. Por ese motivo, el método de la investigación no es axiomático. Y, por ende, es de esperar que la metafísica de las costumbres no inicie con Definitionen. Nuestro argumento aquí no afirma que el método expositivo de la MS sea diferente del axiomático. Este trabajo no estudia el método expositivo de ese texto. Lo que hemos intentado señalar es que la referencia al texto de Hausen y la respuesta kantiana a una objeción posible en el paratexto de la MS representa una referencia a una doctrina de la metafísica que Kant ha desarrollado en otros textos y que implica que ella contiene un uso de la razón que es diferente del uso matemático. Como consecuencia de ello, el método expositivo de la metafísica no debe ser el método axiomático, que parece ser el adecuado para exhibir y desarrollar el conocimiento matemático.

\section{La metafísica de las costumbres no es una antropología.}

Ahora bien, en esta introducción Kant no sólo separa la metafísica de la 
matemática, algo que por lo demás es un tema usual en sus investigaciones teóricas, sino que además se interesa por especificar la diferencia y la relación entre la metafísica y la antropología. La antropología es la ciencia que se ocupa de la naturaleza peculiar del hombre. Es una ciencia empírica. Por ese motivo, no puede proporcionar el fundamento para la determinación de la metafísica de las costumbres. Como ésta es una metafísica, es decir una ciencia racional y pura, no puede basarse en los conocimientos proporcionados por una ciencia empírica.

Sin embargo, esto no significa que no haya ninguna relación entre la metafísica de las costumbres y la antropología. Para Kant, por el contrario, se trata de dos ciencias complementarias. La antropología moral proporciona las condiciones de la naturaleza humana en las cuales se realizan las leyes que investiga la metafísica de las costumbres. Las características de la naturaleza humana pueden propiciar u obstaculizar la realización de las leyes morales. Por lo tanto, la ciencia que estudia la libertad del arbitrio, es decir: la filosofía práctica, contiene tanto una metafísica de las costumbres, que investiga la legalidad moral, como una antropología moral. Ambas resultan necesarias para comprender cómo el libre arbitrio se determina a actuar. Hemos visto que Kant indica esto desde antes en las lecciones de metafísica.

Hay otra relación entre la antropología y la metafísica de las costumbres que Kant apenas señala, y que no explica en detalle. Se trata de lo siguiente. Como la posibilidad de una legislación universal, lo cual es la condición de la moral, supone contar con principios a priori, que tienen su origen en la razón, entonces todo hombre debe tener en sí mismo una metafísica de las costumbres. La posibilidad de una legislación universal supone principios a priori porque la determinación empírica sólo puede proporcionar generalizaciones inductivas, pero no es bastante para asegurar la legalidad irrestricta. ${ }^{27}$

Ahora bien, según lo que hemos argumentado, la naturaleza del hombre debe incluir una metafísica de las costumbres. Esto no significa que conozcamos clara y distintamente esa metafísica. En cambio, la encontramos entre nuestras representaciones de manera oscura, sin conciencia. Entre nuestras representaciones oscuras se cuenta la ley

27 MS, AA 6:216. 
moral. Esta ley, de la que no siempre tenemos consciencia, está involucrada en la naturaleza racional del hombre. La ley tiene su origen en la razón y es por ese motivo un producto necesario de las facultades del hombre. La constitución de éste, el tema que investiga la antropología, involucra la ley moral- tengamos conciencia de ello, o no.

Ese hecho hace de la metafísica de las costumbres una ciencia urgente. Para Kant, la metafísica en general es una ciencia que debe analizar representaciones oscuras y confusas y volverlas claras y distintas. ${ }^{28}$ Entre nuestras representaciones oscuras y confusas tenemos una representación que es central porque es una condición para la determinación de un arbitrio que el libre; se trata, a saber, de la representación de la ley moral. La necesidad de una metafísica de las costumbres hunde sus raíces en la naturaleza del hombre.

Kant también se ha ocupado de la relación de la moral con la antropología en las lecciones de antropología. En estos textos resulta ligeramente más confusa la relación entre ambas ciencias. Parece referirse al carácter complementario de la antropología y la metafísica de las costumbres a I que hemos hecho referencia algunas líneas antes en este trabajo. Cierta antropología puede ser pensada como una parte de la moral. En los apuntes de antropología Mrongovius, del WS 1784/85, leemos que la antropología proporciona los fundamentos de los móviles para la moral. Es decir que la investigación empírica de la naturaleza humana permite comprender las razones por las que el hombre tiene una conducta moral. Más aún, el estudio de la naturaleza humana permite explicar la aplicabilidad de la moral en el mundo. Sin la antropología, la moral sería mero conocimiento de escuela. ${ }^{29}$ Posteriormente, en los apuntes de Antropología Busolt, de $1788 / 89$, se indica que la antropología es de gran utilidad para la moral en la medida en

28 La oscuridad de las representaciones no involucra para Kant que ellas sean inexistentes o inaccesibles. Son oscuras aquellas representaciones de las que no tenemos conciencia. Es decir, cuando al representarnos no identificamos una representación entre nuestras representaciones, esa representación es oscura. Hay filósofos, como Locke, que consideran que este tipo de representaciones no existe y que todas nuestras representaciones son conscientes. Kant se ocupaba de refutar esta tesis en sus lecciones de Antropología. Para él, que tenemos representaciones oscuras es algo que se sabe por inferencia a partir de ciertas conductas que suponen representaciones no expresas, como los prejuicios y los juicios provisionales. Cf. MARTÍNEZ, L. M. "Las nociones de claridad y oscuridad en los Apuntes de Lecciones de Antropología de la 'década silenciosa' de Kant". En: Studia Kantiana, 17, 2014, pp. 27-50.

29 V.-Anth./Mrong, AA 23:1214. 
que proporciona a los deberes que ésta contiene la fuerza de sus móviles. ${ }^{30}$

\section{La metafísica de las costumbres no es una lógica.}

Hay un aspecto de la caracterización de la metafísica de las costumbres que Kant no desarrolla en los paratextos del libro de 1797. Se trata, a saber, de la diferencia específica entre dos ciencias: la lógica y la metafísica. Nuestro filósofo, empero, sí hacía referencia a ese tema en sus clases, de acuerdo con el testimonio disponible.

El apunte conocido como la Metafísica Dohna corresponde al WS de 1792/3. La primera indicación que encontramos en él es una crítica a la concepción de la metafísica que tenía Baumgarten, que seguía a Wolff. Para Kant, la definición que ellos proporcionaban, según la cual la metafísica es la ciencia de los primeros principios de nuestro conocimiento, es inadecuada por ser demasiado amplia. Esa caracterización no es suficiente para indicar la especificidad de la metafísica porque, en rigor, exhibe los rasgos de todas las ciencias.

Para especificar con precisión la metafísica, el texto proporciona una aproximación gradual hacia ella. En primer lugar, la filosofía en general se presenta, nuevamente en estos apuntes, como una ciencia del conocimiento racional por conceptos. Se diferencia de la matemática que es una ciencia racional por construcción de conceptos. Y ambas se diferencian de la Lógica, que es una ciencia formal, que hace abstracción del contenido de nuestros conocimientos y sólo se ocupa de sus reglas formales ${ }^{31}$. La filosofía, que es una ciencia que tiene contenido y cuyos conocimientos son racionales y discursivos, puede ser pura o aplicada. La metafísica es una filosofía pura.

La escolástica aristotélica la ha definido como la ciencia que viene después de la física. A partir de allí, puede pensarse que ella trasciende los objetos sensibles: es una ciencia de lo suprasensible. Ahora bien, si queremos definir la metafísica, podemos decir

V.-Anth./Bus., AA 23:1437.

31 Esta distinción, como hemos advertido, es usual en los apuntes de clase reseñados. También se encuentra explicada en un texto previo al período que nos ocupa, pero importante para la investigación de la filosofía práctica de Kant: la Fundamentación para la metafísica de las costumbres (GMS), de 1785. En el prólogo de este libro, Kant afirma que la metafísica es una filosofía pura referida a ciertos objetos del entendimiento, y no meramente formal como la lógica. Cf. GMS, AA 4:338. 
que es una ciencia que contiene el conocimiento racional puro de los objetos. En este sentido, se encuentra separada de lo empírico y se identifica con la matemática. ${ }^{32}$

A continuación, encontramos dos clasificaciones de las disciplinas filosóficas. En primer lugar, los antiguos trazaban una tricotomía. Las disciplinas filosóficas eran la lógica, la ética y la somatología y la física. En las lecciones, Kant proponía, en cambio trazar una dicotomía, distinguiendo la filosofía formal, es decir la lógica, de las filosofías materiales, que a su vez pueden distinguirse de acuerdo a su objeto: la naturaleza y la libertad. La metafísica es la doctrina pura de la naturaleza. La moral es la doctrina pura de la libertad.33

La metafísica es una ciencia, como señalaban los antiguos, en la que la razón va más allá de los límites de la sensibilidad. Pero esto no puede hacerse en el uso especulativo, sino sólo en el uso práctico de la razón. El problema de muchos filósofos ha sido precisamente cómo ascender de lo sensible a lo suprasensible. ${ }^{34}$ La metafísica es imprescindible para el hombre. Pues con el conocimiento empírico sólo alcanza lo finito, pero él aspira también a lo infinito. Esto es lo suprasensible. El fin de la metafísica es el conocimiento de lo suprasensible. ${ }^{35}$ En estas lecciones, encontramos ya explícitamente exhibida la definición de la metafísica que, según Rivero, corresponde al período de los Progresos.

Finalmente, contamos con los apuntes de Metafísica K3. Nuevamente en ellos leemos que la metafísica pertenece a la parte material de la filosofía, en contraposición con la lógica, que es formal. Además, se reitera su diferenciación con respecto a la matemática. Esta ciencia no se refiere a los límites de nuestro conocimiento de las cosas, el cual es el tema de la metafísica, sino que se ocupa de conceptos hechos por construcción. Finalmente, la metafísica se distingue de las ciencias empíricas. Los conocimientos de la metafísica deben ser conocimientos racionales a priori, cuyos principios se relacionan según un orden necesario, racional e independiente de la

\footnotetext{
V.-Met/Dohna, AA 28:616.

V.-Met/Dohna, AA 28:616.

V. Met./Dohna, AA 28: 618.

V. Met./Dohna, AA 28: 620.
} 
experiencia. La metafísica es "el sistema de la filosofía pura", "el sistema de los conocimientos racionales por conceptos".36

Asimismo, en estos apuntes encontramos la objeción a la definición wolffiana que se reproduce en el manual de Baumgarten. Nuevamente, Kant señala que esa definición es insatisfactoria y no permite determinar la disciplina que va a estudiarse.37 Además, se repite la referencia etimológica del término, según la cual la metafísica es el conocimiento de aquello que está más allá de la naturaleza. Es una ciencia en la que sólo podemos conocer por medio de la razón. Los objetos que pueden conocerse de esta manera son tres, a saber: Dios, la libertad y la inmortalidad. Esos tres objetos, prosigue el apunte, son conceptos puros de la razón. No pueden ser exhibidos fenoménicamente, de modo que sólo pueden ser pensados. Por este motivo, en contraposición con los fenómenos, pueden ser denominados objetos suprasensibles, noúmena.38

La metafísica, de este modo, se presenta como una ciencia, es decir un sistema de conocimientos, que tiene por objetos conceptos de la razón que no pueden ser exhibidos en la intuición y que por lo tanto trascienden el ámbito de lo sensible. La metafísica es una ciencia de lo suprasensible. No es una ciencia formal, es una ciencia que se ocupa de una parte de nuestro conocimiento. En particular, se interesa por objetos que no pueden ser exhibidos en la intuición y, por eso, pertenecen al ámbito de lo suprasensible. Si la contraposición con la matemática permite a Kant especificiar cuáles son los procedimientos de la metafísica y la contraposición con la antropología permite enfatizar en su pureza, la contraposición con la lógica apunta a indicar con claridad que la metafísica de las costumbres se ocupa de un peculiar tipo de objeto, y no de la naturaleza del pensar en general.

\section{El tema de la metafísica de las costumbres.}

Los conceptos de la razón que constituyen el tema de la metafísica son tres: Dios, la libertad y la inmortalidad. Es por esto que la moral, la filosofía práctica, la ética o la 
metafísica de las costumbres constituyen una parte de la metafísica. En diferentes textos, Kant parece referirse a la misma ciencia empleando esos nombres. Ahora bien, se trata de la parte que resulta excluída en los cursos de metafísica que dictaba Kant. Si bien el problema de la libertad y la determinación del arbitrio se inscriben en el ámbito de interés de la metafísica, Kant no se ocupaba de esos temas en sus lecciones de metafísica. En cambio, encontramos registros de que el filósofo dictaba cursos específicos sobre esos temas. $^{39}$

De acuerdo con la información proporcionada en el sitio Kant in the Classroom ${ }^{40}$, el curso de Filosofía moral fue dictado por Kant en numerosas ocasiones a lo largo de su carrera como profesor, recibiendo el nombre de "ética", "filosofía moral", "filosofía práctica" o "metafísica de las costumbres". En el período de tiempo que nos interesa estudiar, Kant dictó dos cursos en esta disciplina. En el WS de 1788/89, el curso se tituló "Philosophiam practicam universalem una cum Ethica". El curso del WS de 1793/94 se tituló "Metaphysik der Sitten oder Allgemeine praktische Philosophie samt Ethik nach Baumgarten". Sólo contamos con apuntes de este último curso, conocidos como las Lecciones de Metafísica de las costumbres Vigilantius.

En esas lecciones, en el marco de un intento de determinar el objeto que ha de estudiarse durante el curso y en el contexto específico de una clasificación de las partes de la filosofía basada en su objeto, leemos que hay una parte de la filosofía que se ocupa de las leyes de las costumbres [Sittengesetze]. Su tarea consiste en desarrollar la idea de la libertad. Esa ciencia, pues, encuentra su fundamento en conceptos de la razón, que son puros. ${ }^{41}$

En el mismo texto, en efecto, leemos que la metafísica de las costumbres "se ocupa del uso de la libertad del arbitrio humano según las reglas del derecho". ${ }^{42}$ ¿Qué significa esto? ¿Qué involucra la libertad del arbitrio humano? ¿Cuáles son las reglas del derecho?

39 En las anotaciones póstumas conocidas como Los progresos de la metafísica, redactadas a principios de la década de 1790, Kant explicita esa separación. Allí, en el segundo manuscrito, se especifica que en ese texto se considera la metafísica como ciencia teórica, excluyendo la metafísica de las costumbres. Cf: FM, AA 20:293.

40 http://www.manchester.edu/kant/Home/index.htm

41 V.-MetS/Vig., AA 27:479.

42 V.-MetS/Vig., AA 27:480. 
¿Cómo puede ser libre un arbitrio reglado? La libertad del arbitrio se caracteriza en ese texto como un ejercicio pleno de las facultades. Esa libertad es independiente de la experiencia, en la medida en que sólo se refiere a la razón. Es la sola razón la que da la regla que legisla sobre el arbitrio. La razón proporciona la ley en conformidad con la cual se determina el arbitrio para la acción y en eso consiste ser libres. Ahora bien, ¿qué relación tiene todo esto con el derecho?

El concepto del derecho se identifica en el texto con la idea racional de la obligación [Verpflichtung]. Y es aquello sobre lo que se construye la metafísica de las costumbres. Ese concepto no tiene su origen en la experiencia, pues es un concepto racional. Sin embargo, él se asienta en la realidad [Realität], pues aquello que la razón manda incondicionadamente debe ser posible. Es decir, que el concepto del derecho es un concepto que tiene su origen en la razón y manda incondicionadamente, pero, justamente por este hecho, contiene en sí mismo la posibilidad de aquello que manda. Aquello que la razón ordena al arbitrio es posible, y su posibilidad no debe buscarse en la experiencia. Si la experiencia contradijera el mandato, eso no lo cancelaría. El mandato es incondicionado y su realidad está contenida en él mismo. Porque el concepto del derecho contiene en sí mismo su realidad y como la metafísica tiene ese concepto como principio, su aplicabilidad no puede ser puesta en duda, contra ciertas pretensiones de los empiristas. ${ }^{43}$

La doctrina de las costumbres, es decir la filosofía moral, se funda en la doctrina del deber [Pflicht]. Es deber actuar en conformidad con la ley moral. ${ }^{44}$ La Ética es la doctrina de la moralidad de nuestras acciones. La doctrina del derecho se ocupa de la legalidad de nuestras acciones. La Moral tiene por objeto las reglas del deber. Estas reglas son prácticas, y no teoréticas: se ocupan de las condiciones de aquello que debe ser, y no de las condiciones de lo que es. ${ }^{45}$

Eso es lo que afirma Kant en las lecciones a las que hemos hecho referencia. En la MS, puede encontrarse una explicación del objeto de esta ciencia en la tercera sección de la introducción, que se titula "División de una metafísica de las costumbres". Allí leemos en

$43 \quad$ V.-MetS/Vig, AA 27:480.

44 V.-MetS/Vig, AA 27:481.

45 V.-MetS/Vig, AA 27:491. 
primer lugar que la metafísica de las costumbres, en sus dos partes, se ocupa de una legislación que determina al arbitrio libre. Por medio de la explicación de la naturaleza de esa legislación, Kant diferencia los temas de su libro: la ética y la legalidad jurídica. Si la legislación tiene un aspecto objetivo que hace que ciertas acciones sean un deber y un aspecto subjetivo que hace de ese hecho un móvil para la conducta, una legislación ética es la que considera la acción como deber y la deber como móvil, en tanto que una legislación jurídica no contiene el último elemento. Esto quiere decir que la legilación jurídica es independiente de la determinación subjetiva que hace del deber un móvil. ${ }^{46}$

Vemos que, al margen de esta diferencia entre los objetos de cada parte de la metafísica de las costumbres, en ambos casos ella se ocupa de una legislación en la que ciertas acciones se presentan como deber. Esta legislación se funda en la libertad, que es la causalidad de la razón para determinar el arbitrio, independientemente de otras condiciones de la experiencia. ${ }^{47}$ Esa libertad es un concepto de la razón, que en su uso teórico no puede aprehenderla, en la medida en que no está dada en la experiencia. El concepto de la libertad es un concepto suprasensible. La metafísica de las costumbres debe hacer el tránsito desde la sensibilidad hacia ese concepto de cuya realidad sólo tenemos testimonio en virtud del uso práctico de la razón.

\section{Recapitulación.}

El objetivo de este trabajo era retomar las notas del concepto de metafísica que se encuentra en el libro La metafísica de las costumbres, de 1797. Para ello, hemos recurrido a dos tipos de fuentes, las cuales son, a saber, los paratextos de ese libro y los apuntes de clase de la época. En primer lugar, hemos acotado el período del pensamiento de Kant correspondiente al texto que nos ocupa, a partir de la revisión de las discusiones al respecto. En segundo término, hemos revisado las definiciones de la metafísica que se encuentran en las fuentes. En estas definiciones, hemos hallado tres rasgos principales de esta ciencia: i. su carácter sistemático, ii. su pureza, iii. su discursividad. En tercer lugar, nos

\footnotetext{
46 MS, AA6:219.
}

47 MS, AA 6:221. 
hemos centrado en el aislamiento de la ciencia, por medio de una triple diferenciación: i. con respecto a la otra ciencia racional pura, la matemática, ii. con respecto a la otra parte de la filosofía práctica, la antropología moral, iii. con respecto a otra investigación que contiene referencias a los conceptos puros, la lógica. Esta última diferencia ha motivado que nos concentráramos en la materia de la metafísica de las costumbres, pues es el hecho de referirse a un tipo de objetos, y no a las condiciones formales del pensar en general, lo que la diferencia de la lógica. En nuestro último apartado, hemos introducido algunas consideraciones generales acerca del tema de una metafísica de las costumbres, según los textos del mismo Kant. 


\section{Bibliografía}

- CORTINA ORTS, Adela (1989). "Estudio preliminar". En: KANT, Immanuel, La metafísica de las costumbres. Madrid, Tecnos, 1989

- DRIESCH, Hans, "Kant und das Ganze". En: Kant Studien, 29, 1924

- KANT, Immanuel. Kant's gesammelte Schriften. Ed. de la Königlich Preußischen Akademie der Wissenschaften und ihren Nachfolgern. Berlin y Leipzi, 1724-1804.

- MARTínEZ, L. M. "Las nociones de claridad y oscuridad en los Apuntes de Lecciones de Antropología de la 'década silenciosa' de Kant". En: Studia Kantiana, 17, 2014

- MOledo, F. "Die neue Auffassung der Metaphysik als reine Philosophie in der Inauguraldissertation und ihre propädeutische Bedeutung $m$ Rahmen der Entwiklungsgeschichte der KrV". En: Kant-Studien, 2015

- SÁNCHEZ RODRÍGUEZ, Manuel. "La teoría de los tipos de representación en Leibniz y sus principales influencias en la estética y la lógica de la llustración alemana". En: Cultura. Revista de História E Teoria Das Ideias (Universidade Nova de Lisboa, 2014.

- VÁZQUEZ LOBEIRAS, M. J. "La ética kantiana como una parte de la metafísica. Reflexiones en torno a la evolución del pensamiento ético de Kant en el bicentenario de la Metafísica de las costumbres (1797-1997)". En CARVAJAL CORDÓN, J. (Ed.), Moral, derecho y política en Immanuel Kant. La Mancha, Cuenca, 1999

- WOLFF, Christian. Discursus praeliminaris de philosophia in genere. Einleitende Abhandlung über Philosophie im allgemeinen. Edición histórico crítica bilingüe de Günter Gawlick y Lothar Kreimenthal. Stuttgart-Bad Cannstatt, 1991 